\title{
Epidemia de peste porcina africana: estado actual
}

Consuelo Carrillo, DVM, PhD

${ }^{1}$ Senior Advisor in Animal Health in Diagnostic Services (DSS)

Foreign Animal Diseases Diagnostic Laboratory (FADDL)

National Veterinary Services Laboratories (NVSL)

USDA-Animal and Plant Health

Inspection Service (APHIS)

Plum Island Animal Disease Center

P.O. Box 848

Greenport, NY 11944

Autor para correspondencia:

Oficina: (631) 323-3352

Correo electrónico:

consuelo.carrillo@usda.gov
Aceptado: 2020-09

Publicado: 2020-09-30

Información y declaraciones adicionales en la página 18

\section{(c) Derechos de autor:}

Consuelo Carrillo 2020

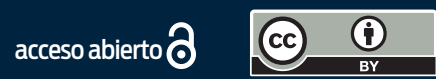

Distribuido bajo una Licencia Creative Commons Atribución 4.0 Internacional (CC-BY 4.0)

\section{Resumen}

La peste porcina africana es una infección viral no zoonótica que se transmite por contacto y por garrapatas. Su notificación debe ser inmediata y es obligatoria. Afecta a cerdos domésticos y silvestres con diversas manifestaciones clínicas. En cerdos domésticos y jabalíes, la presentación clínica es muy similar a la de peste porcina clásica (también conocida como cólera porcino), por lo que es imprescindible una correcta toma de muestras y un rápido envío al laboratorio para lograr un diagnóstico diferencial. Los ciclos de infección se presentan de dos formas: a) selvática, en la que el virus permanece en circulación durante largos períodos entre las garrapatas y los animales persistentemente infectados, y b) epidémica, que involucra a cerdos domésticos y jabalíes, pero raramente se encuentra en los vectores. Los principales signos son fiebre, letargia, y muerte súbita en casos sobreagudos. Si el animal resiste algunos días, se observan diarreas y vómitos con fuertes hemorragias y emaciación de la piel. Los casos más moderados dejan un cierto porcentaje de animales sobrevivientes que permanecen como transmisores de la enfermedad. También pueden existir portadores asintomáticos. No hay tratamiento ni vacunas, por lo que el control de la enfermedad se fundamenta en una detección rápida y en el sacrificio obligatorio de todos los individuos afectados y sospechosos de haber estado en contacto con el virus. La peste porcina africana es endémica en África, Europa del este, China y parte de Asia.

Palabras clave: Virus; Virus ADN; Peste porcina; Enfermedades rojas del cerdo; Peste porcina clásica; Cólera porcino; CSF; PPC; African swine fever; ASF; Diagnóstico; ASF, vacunas

Cite this as:

Carrillo C. Epidemia de peste porcina africana: estado actual. Veterinaria México OA. 2020;7(3). doi: 10.22201/ fmvz.24486760e.2020.3.930 


\section{Introducción}

La peste porcina africana (PPA; conocida por su denominación en inglés, African swine fever [ASF]) es una infección viral de los suidos domésticos y silvestres, que también replica y se transmite en garrapatas del género Ornitodorus. ${ }^{1}, 2 \mathrm{Su}$ epidemiologia y transmisión son complejas y aún bastante desconocidas. Asimismo, existen grandes lagunas de conocimiento acerca de la biología del virus, su patogenia y la respuesta inmune del hospedero, lo que dificulta el control de los brotes y la prevención de la enfermedad en los países en los que no es endémica. Debido a su elevada mortalidad, el sacrificio obligatorio y el consecuente impacto económico en la industria pecuaria, su notificación es obligatoria e inmediata a través de los organismos internacionales de salud animal (OIE y FAO). No existe tratamiento, y aunque hay algunas vacunas en fase experimental y de registro, ninguna ha sido aprobada oficialmente, ni está disponible todavía de manera comercial. Debido a la multiplicidad de presentaciones sintomatológicas, que van desde la muerte súbita en los casos sobreagudos hasta los casos subclínicos de infección crónica, e incluso sin sintomatología, ${ }^{1-5}$ el diagnóstico clínico es ineficaz. Por lo tanto, el diagnóstico de laboratorio resulta el único que permite la confirmación o exclusión del virus de PPA en caso de enfermedad, por lo que es fundamental para la detección, y el control de la enfermedad.

La PPA ha sido históricamente endémica en el continente africano y esporádicamente en países de Centro y Sudamérica, así como de Europa occidental. Se detectó en Portugal en 1957 y 1960 y permaneció en la península ibérica hasta mediados la década de 1990, cuando se erradicó exitosamente y quedó restringida a la Cerdeña como única región endémica dentro del continente europeo. Algunos brotes esporádicos se produjeron también en Cuba en 1971 y1980, en Francia en 1974, en la República Dominicana, Haití, Brasil, Malta e Italia en 1983, y en Bélgica en 1985, rápidamente controlados y extinguidos.

En 2007 se presentó en Georgia, se estableció en la región caucásica, se extendió por toda Rusia y Europa oriental y llegó hasta la frontera de los países nórdicos, amenazando la industria porcina de la Unión Europea. Lo más alarmante es que durante los últimos cinco años, la presencia de PPA se ha extendido a más de 50 países, incluyendo China, el mayor productor mundial de porcinos y cuya población de cerdos se redujo en consecuencia en un 55\% durante 2019. Corea del Sur ha confirmado también casos en jabalíes silvestres infectados con este virus. En Filipinas, el primer brote se informó en julio de 2019 y hasta el momento se cuentan aproximadamente 62.000 cerdos sacrificados. Timor Oriental es la décima nación de Asia que ha informado la presencia de PPA y lleva registrados 100 brotes de la enfermedad en este breve periodo de tiempo. Asimismo, Vietnam, Laos, Myanmar, Corea del Norte, Mongolia y Camboya completan un total de 522 millones de cerdos afectados de una población de 770 millones. ${ }^{5-8}$

Las estrategias para el control de la PPA en los países que presentan la enfermedad por primera vez o bien tienen brotes esporádicos consisten principalmente en seguir las medidas clásicas de intervención de cuarentena y sacrificio obligatorio de todos los animales afectados y sospechosos. La experiencia de los países recientemente afectados por la introducción de esta enfermedad, junto 
con la amenaza al abastecimiento global de una de las principales, y económicamente más asequibles, fuentes de proteína de alta calidad para consumo humano, han evidenciado lo insostenible y poco eficaz de esta metodología. En contraste, los países de África, Asia y Europa oriental, donde la PPA es endémica, exploran medios menos costosos, que les permiten convivir con la enfermedad, aun asumiendo el riesgo de dispersión que eso conlleva. En este sentido, agencias gubernamentales, grupos científicos especializados, consorcios internacionales, y organismos internacionales como la OIE y la FAO han elaborado y publicado informes que describen los temas que deben abordarse con mayor urgencia, y que podrían ayudar a resolver la situación epidémica y endémica de la PPA a escala mundial. ${ }^{5,6,8}$ En este artículo se revisan las herramientas actualmente disponibles y en uso para el control y prevención de la PPA.

\section{Peste porcina africana}

El impacto económico y social de la PPA la califica como una enfermedad de declaración obligatoria a través de la Organización Internacional de Epizootias (OIE-WHO), con graves efectos arancelarios sobre los mercados internacionales de productos pecuarios y animales vivos.

\section{Características del virus}

El agente etiológico de la PPA es un virus tan particular que se ha clasificado como taxonómicamente único; es decir, que representa individualmente a toda la familia Asfarviridae, género Asfivirus, sin que se conozcan virus relacionados. ${ }^{9}$ Es un virus de gran tamaño (alrededor de $200 \mathrm{~nm}$ de diámetro), que replica en el citoplasma de las células que infecta, principalmente macrófagos. Tiene una doble capa proteínica en su exterior, así como una molécula simple de ADN de doble cadena de 170 a 190 mil pares de bases en el interior de la cápside (Figura 1). Los genes en su ADN codifican alrededor de 160 proteínas, muchas de ellas esenciales para la biología del virus, y otras no esenciales, pero que ayudan al virus a modular las funciones de la célula que infecta y a escapar de la respuesta inmune del hospedador. ${ }^{10}$

Después de infectarse con el virus de la PPA, los cerdos domésticos pueden excretarlo de 24 a 28 horas antes de que aparezcan los signos clínicos. Durante la etapa aguda de la enfermedad, se liberan enormes cantidades del virus en todas las secreciones y excreciones corporales, ya que existen altos niveles de éste en los tejidos y en la sangre. ${ }^{11}$

Dada la complejidad y variabilidad de las manifestaciones patológicas que se observan en los brotes de PPA, y a pesar de que el virus se considera como taxonómicamente único, se han establecido 24 genotipos diferentes distribuidos en tres ramas principales, de acuerdo con distintas secuencias genéticas de una proteína en su cápside, conocida como p72. Según esta clasificación, se ha determinado que el genotipo 1 corresponde al virus circulante en África, y que fue éste el responsable de la primera oleada de infecciones en Europa que inició en 

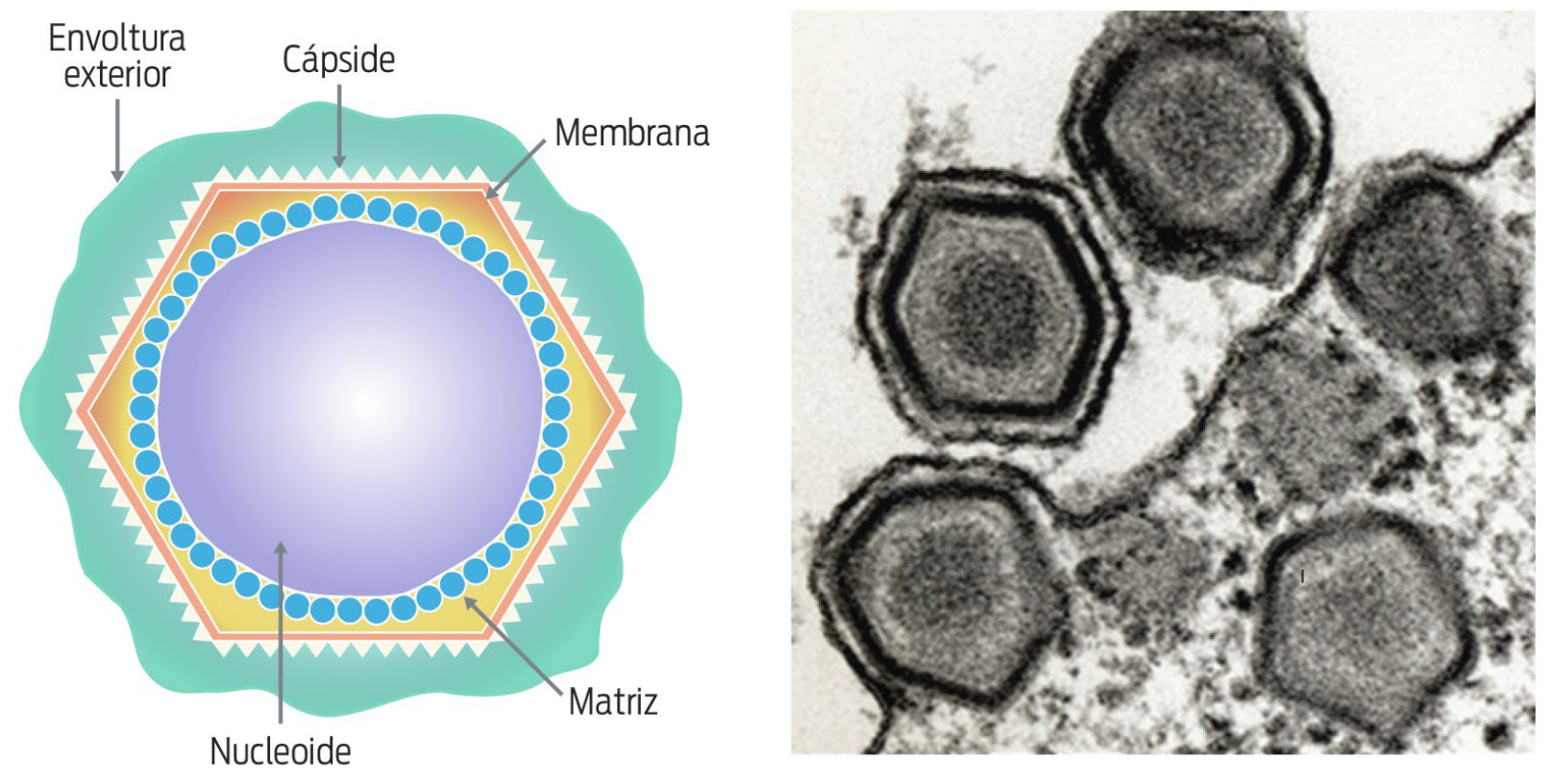

LVR

CVR

RVR

IIIIIIIII

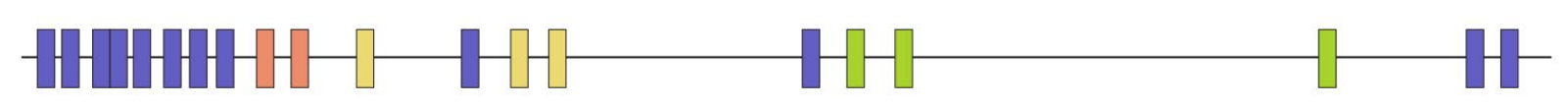

Proteínas estructurales: p30, p72, p54

Modulación de respuesta inmune: 5EL (IkB), 8CR (lectina), 8DR (CD2)

Prevención de apoptosis celular: 5HL (Bcl2), 4CL (iap)

Asociados a virulencia y rango de hospedador: NL, UK, 9GL, MGF, TK

IIIIIIIII Regiones variables

Figura 1. Representación esquemática del virus de la peste porcina africana, imagen por microscopía electrónica y localización de algunos de los genes que han sido caracterizados dentro del ADN viral.

LVR (left variable region): región variable izquierda.

CVR (central variable region): región variable central.

RVR (right variable region): región variable derecha. 
Portugal, mientras que la epidemia actual se debe al genotipo 2 y corresponde, por lo tanto, a una nueva introducción viral.12,13

\section{Patogenia y transmisión}

El virus de la PPA infecta a cerdos domésticos y silvestres, incluyidas distintas especies de jabalíes como Phacochoerus africanus y Potamochoerus larvatus en África, así como al cerdo silvestre (Sus scrofa) en Eurasia. Las primeras descripciones de la infección en cerdos domésticos fueron las de una enfermedad hemorrágica aguda con un $100 \%$ de mortalidad. ${ }^{14}$ Este tipo de cuadro clínico se aprecia aún hoy al inicio de los brotes, pero a medida que pasa el tiempo y se desarrolla un estado endémico, se observan casos subagudos de desarrollo más lento con una menor mortalidad, e incluso formas de infección crónicas e inaparentes que permiten a los animales supervivientes actuar como portadores del virus por periodos indefinidos. Las bases moleculares y/o genéticas de este cambio de virulencia son desconocidas, pero podrían deberse a cambios en el virus que modifican la dinámica de su replicación, su tasa de infección u otros factores dependientes del hospedero.

Se ha informado que un mismo virus produce efectos diferentes en poblaciones de distinta especie o edad, lo que sugiere que quizás la baja virulencia no dependa de cambios en el virus o de la genética del hospedero, sino del resultado de una combinación de elementos desconocidos hasta este momento. ${ }^{15,16}$ En la Figura 2 se ilustra un ejemplo de cómo la vía de inoculación y la dosis viral pueden afectar la patogenia de un mismo aislado virulento de PPA (Georgia 2007). En el cerdo, se cree que las vías más frecuentes de infección son la oronasal y el contacto a través de la piel erosionada o bien perforada con elementos contaminados. Con frecuencia la literatura ha relacionado los brotes con la ingestión de desperdicios de cocina, sangre u órganos de animales muertos, deglución de líquidos contaminados, así como fómites y útiles infectados con el virus. La transmisión por contacto directo entre cerdos se ha documentado de forma experimental, y se ha demostrado que el virus se encuentra en la sangre, fluidos orales, nasales, fecales y en orina de los animales infectados, si bien los tiempos y títulos en los que se presenta varían según el aislado y el tipo de manifestación clínica. La transmisión por aerosol parece limitarse a los casos en los que los animales se encuentran en proximidad extrema, ya que la separación física por medio de muros no permite la dispersión del virus.

Se sabe que el virus de la PPA infecta y se replica exitosamente en las garrapatas del género Ornithodoros. Por otra parte, hay evidencias de que las moscas de establo, tábanos y larvas de mosca pueden retenerlo durante 24 a 48 horas después de haber estado en contacto con sangre infectada. Sin embargo, la importancia de estos últimos como vehículos de la enfermedad se considera insignificante. ${ }^{17-19}$

La dosis infectiva para inoculación experimental por vía oronasal se ha estimado en tan solo de 1 a $10 \mathrm{HAD} 50 / \mathrm{ml}$. Dependiendo del aislado, el huésped y la dosis de infección, la diseminación del virus a otros órganos a través de la sangre toma de 7 horas a 3 días y se realiza por asociación directa de la partícula viral 


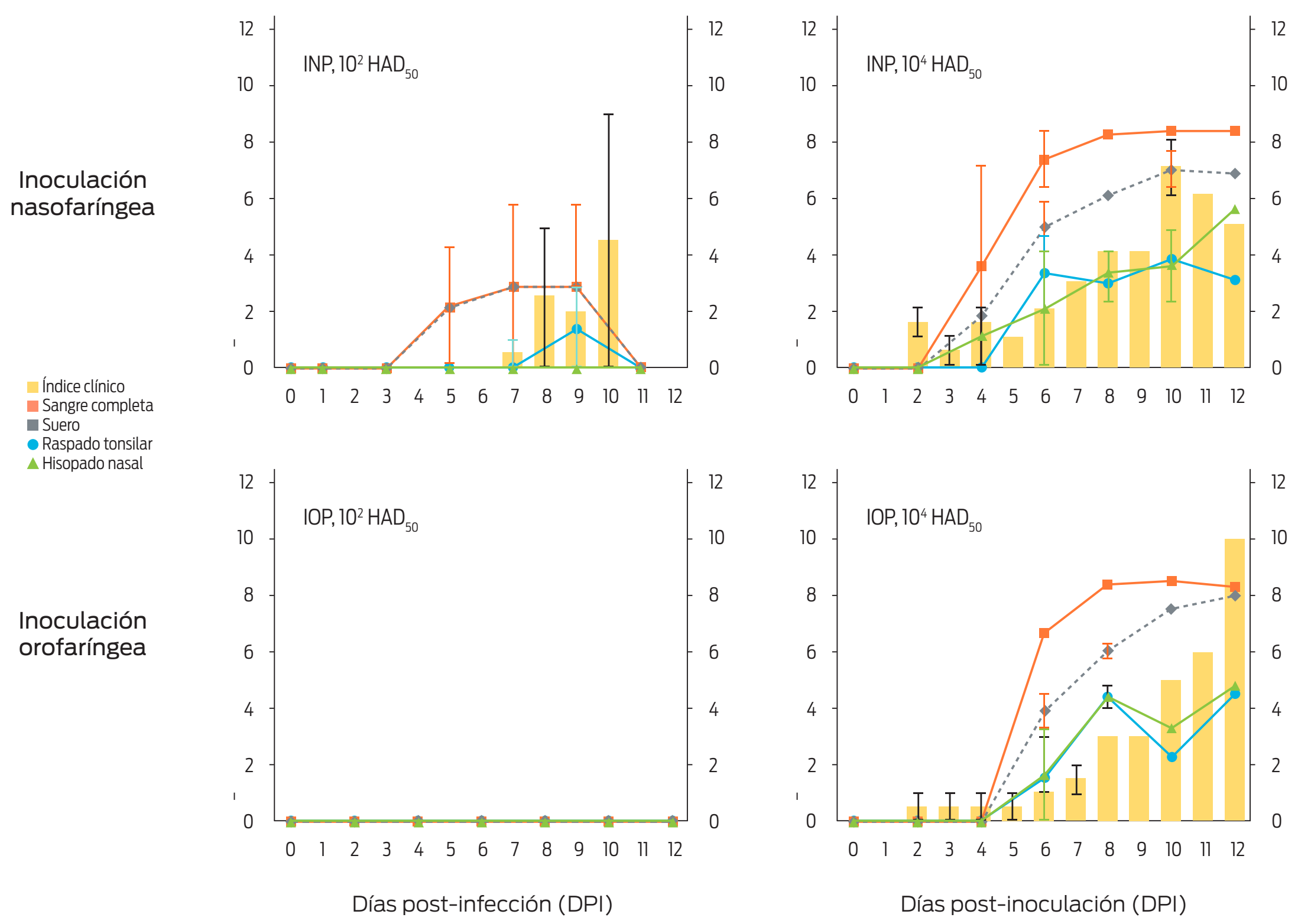

Figura 2. Patogenia de la infección experimental con el aislado Georgia 2007 utilizando cuatro rutas distintas de inoculación en cerdos domésticos. (Obtenido de Howey et al. ${ }^{15}$ ) 
con la superficie de los eritrocitos, linfocitos y neutrófilos. El virus replica inicialmente en la faringe, los pulmones y los ganglios linfáticos, y se reparte después a zonas más distales a través de la linfa y la sangre. El sustrato preferencial son las células del sistema fagocítico mononuclear, predominantemente monocitos y macrófagos. La infección, la sintomatología y la patogenia de la PPA son similares entre los cerdos domésticos y los silvestres. Los caracteres de resistencia a la enfermedad observados en algunas razas africanas de cerdos no parecen ser genéticamente heredables. ${ }^{20}$

\section{Vacunas e inmunología}

Desde la década de 1950 se sabe que existe protección homóloga; es decir, que el animal recuperado de la infección con un determinado aislado de PPA permanece resistente de por vida a la reinfección con ese mismo aislado (homólogo), pero puede sucumbir a la infección con otra cepa distinta de PPA (cepa heteróloga). En la década de 1990 se demostró que la transferencia pasiva de los anticuerpos provenientes del suero de animales protegidos proporciona inmunidad contra la infección. ${ }^{21-23}$ Por lo tanto, si el animal resiste la enfermedad por tiempo suficiente, se produce una respuesta inmune con títulos altos de anticuerpos circulantes, que son determinantes en la protección ante una nueva infección con el mismo virus, pero que no protegen de otras cepas virales y cuya capacidad neutralizante in vitro no se ha demostrado. Así, mientras que se han probado la existencia y el efecto protector de los anticuerpos en suero, sus propiedades de neutralización cruzada in vitro no se correlacionan con lo observado in vivo, por lo que los elementos que definen, agrupan y diferencian los aislados naturales en homólogos y heterólogos son aún desconocidos. No obstante, resultados preliminares in vitro obtenidos con la técnica de inhibición de la hemadsorción parecen sugerir que los virus de un mismo grupo hemadsorbente tienen reactividad cruzada, mientras que los de diferentes grupos no. Además, los anticuerpos inhibidores de la infección de monocitos (M-II) inhiben la replicación de virus en cultivo de macrófagos, siguiendo el patrón de protección cruzada que se observa in vivo. ${ }^{24}$ También se han identificado las funciones de algunos genes importantes en la modulación de la respuesta inmune que incluyen a los inhibidores del interferón (tipo I), inhibidores de la apoptosis, factores de virulencia y factores que afectan el rango de hospedador. ${ }^{25-32}$ Con todo, aún queda mucho por descubrir en cuanto a los mecanismos de protección inmune contra esta enfermedad.

Las evidencias acumuladas a través del tiempo han llevado al desarrollo de una variedad de probables vacunas: a) utilizando virus inactivados: se sabe que si el virus no replica no se generará ninguna respuesta inmune; es decir, un virus no infeccioso completo o en fragmentos antigénicos, con o sin adyuvantes y estimulantes de la inmunidad, no induce protección contra la infección; b) utilizando subunidades virales: algunos resultados hasta el momento han sido alentadores, pero la protección es parcial; c) utilizando virus vivos atenuados: aunque son las vacunas más prometedoras, ya que tienen un 100\% de protección homóloga, este tipo de vacunas presenta riesgos de bioseguridad como efectos adversos, persistencia de la infección y reversión a virulencia. No obstante, gracias a los recientes 
esfuerzos para avanzar en el conocimiento de la biología, la genómica y la patogenia del virus natural (no atenuado) en cerdos domésticos, se han desarrollado los primeros candidatos a vacuna en forma de mutantes virales atenuadas por deleción genética de uno o varios factores específicos de virulencia. La manipulación genética del virus tiene la ventaja añadida de poder incorporar marcadores genéticos que permitan la fácil diferenciación entre individuos vacunados e infectados. ${ }^{33-35}$

En ausencia de vacunas, el único sistema de prevención y control se basa en establecer programas intensos de vigilancia y detección temprana, para lo cual el diagnóstico precoz y la transparencia en los resultados son los pilares más importantes para una política nacional e internacional de salud animal exitosa.

\section{Diagnóstico}

No existe tratamiento ni vacuna para la PPA, por lo que la única forma efectiva de prevenirla y controlarla se basa en una detección temprana y precisa, que permita evitar la introducción legal o ilegal de animales infectados o sus derivados en áreas libres de la enfermedad. Las medidas sanitarias recomendadas para el control y erradicación de brotes son drásticas y costosas, e incluyen el sacrificio obligatorio no sólo de animales enfermos, sino también de aquellos sospechosos de haber estado en contacto directo o indirecto con el virus. Antes de proceder a la declaración de un brote de PPA es necesario asegurarse y confirmar inequívocamente que se trata del virus de la PPA, por lo que los signos clínicos observados en el campo deben acompañarse del diagnóstico confirmatorio con técnicas de laboratorio debidamente controladas y validadas según los estándares internacionales.

\section{Diagnóstico clínico}

La observación de signos clínicos constituye el primer frente de detección y aviso, por lo que la capacitación, difusión y educación continua de veterinarios, productores, cazadores y operarios (en el campo, ferias, mercados y granjas) es esencial. De hecho, el principal problema para la detección de enfermedades exóticas es que se excluyen de la rutina de observación clínica, lo que retrasa su sospecha y confirmación, hasta que se han descartado afecciones más comunes y que producen un cuadro clínico similar. Este tiempo de retraso impacta las repercusiones del brote, ya que permite una mayor distribución geográfica de la enfermedad. Además, es importante insistir en que es fundamental reconocer las distintas presentaciones clínicas y estar preparado para recolectar y enviar las muestras necesarias para una confirmación diagnóstica en el laboratorio, que lleve a la pronta resolución de los casos.

Los signos clínicos de la PPA dependen de la combinación de una serie de factores como: virulencia del aislado, dosis de infección, características genéticas del hospedador, estado de salud del animal antes de la infección y capacidad de respuesta inmune, entre otros. Por ello, a menudo el cuadro clínico observado 
Tabla 1. Formas clínicas de la peste porcina africana

\begin{tabular}{|c|c|c|c|c|c|}
\hline Virulencia & Alta & Alta & Moderada & Baja & Baja \\
\hline Cuadro clínico & Sobreagudo & Agudo & Subagudo & Crónico & Asintomático \\
\hline Mortalidad & $100 \%$ & $90-100 \%$ & $60-90 \%$ & $20-60 \%$ & $2-20 \%$ \\
\hline $\begin{array}{l}\text { Incubación post- } \\
\text { infección }\end{array}$ & Inapreciable & 7-7 dpi & $6-15 \mathrm{dpi}$ & $\begin{array}{c}\text { Semanas, incluso } \\
\text { meses }\end{array}$ & Inapreciable \\
\hline Fiebre & Muy alta, $>42{ }^{\circ} \mathrm{C}$ & Muy alta, $>40^{\circ} \mathrm{C}$ & $\begin{array}{l}\text { No excede los } \\
40^{\circ} \mathrm{C}\end{array}$ & $\begin{array}{l}\text { Inapreciable o muy } \\
\text { leve }\end{array}$ & $\begin{array}{l}\text { Inapreciable o } \\
\text { inexistente }\end{array}$ \\
\hline Piel & $\begin{array}{l}\text { Eritema post } \\
\text { mortem }\end{array}$ & $\begin{array}{l}\text { Eritema, } \\
\text { petequias }\end{array}$ & $\begin{array}{c}\text { Eritema, cianosis, } \\
\text { petequias }\end{array}$ & $\begin{array}{l}\text { Hiperpigmentación, } \\
\text { necrosis focales, } \\
\text { hematomas }\end{array}$ & $\begin{array}{l}\text { Hiperpigmentación, } \\
\text { necrosis focales, } \\
\text { hematomas }\end{array}$ \\
\hline Comportamiento & $\begin{array}{l}\text { Muerte súbita en } \\
\text { menos de 4-6 dpi }\end{array}$ & $\begin{array}{l}\text { Apatía, } \\
\text { inapetencia, } \\
\text { hacinamiento, } \\
\text { somnolencia, } \\
\text { muerte 6-9 dpi }\end{array}$ & $\begin{array}{l}\text { Letargia, } \\
\text { inapetencia, } \\
\text { desorientación, } \\
\text { muerte 6-9 dpi }\end{array}$ & $\begin{array}{l}\text { Letargia o normal, } \\
\text { muerte de algún } \\
\text { animal a los meses } \\
\text { de la infección }\end{array}$ & $\begin{array}{l}\text { Normal, muerte } \\
\text { de algún animal } \\
\text { a los meses de la } \\
\text { infección }\end{array}$ \\
\hline Síntomas & Inapreciables & $\begin{array}{l}\text { Vómitos y } \\
\text { diarreas, } \\
\text { hemorragias, } \\
\text { convulsiones, no } \\
\text { sobrevivientes }\end{array}$ & $\begin{array}{l}\text { Vómitos y } \\
\text { diarreas, } \\
\text { hemorragias, } \\
\text { convulsiones, hay } \\
\text { sobrevivientes }\end{array}$ & $\begin{array}{l}\text { Conjuntivitis, } \\
\text { vómitos y diarreas, } \\
\text { abortos, tos, hay } \\
\text { supervivientes }\end{array}$ & $\begin{array}{l}\text { Conjuntivitis, } \\
\text { diarreas, abortos, } \\
\text { artritis, tos }\end{array}$ \\
\hline $\begin{array}{l}\text { Hallazgos } \\
\text { a la necropsia }\end{array}$ & Inapreciables & $\begin{array}{l}\text { Esplenomegalia, } \\
\text { petequias, } \\
\text { ganglios } \\
\text { infartados, } \\
\text { hemorragias, } \\
\text { edema pulmonar }\end{array}$ & $\begin{array}{c}\text { Esplenomegalia, } \\
\text { petequias, } \\
\text { ganglios } \\
\text { infartados, } \\
\text { hemorragias, } \\
\text { abortos }\end{array}$ & $\begin{array}{c}\text { Pleuritis, neumonía, } \\
\text { pericarditis, a veces } \\
\text { hemorragias }\end{array}$ & $\begin{array}{c}\text { Pleuritis, } \\
\text { consolidación } \\
\text { pulmonar, } \\
\text { pericarditis fibrinosa }\end{array}$ \\
\hline
\end{tabular}

\footnotetext{
* dpi: días post-infección
}

en el campo no se parece al descrito por los expertos en los libros, que generalmente describen lo observado a partir de infecciones experimentales, o bajo situaciones epidémicas que se relacionan a un sistema productivo particular y a la bioseguridad. ${ }^{36-40}$

Al inicio de los brotes de PPA, los casos corresponden a una enfermedad sobreaguda o aguda, con fuertes hemorragias que producen la muerte inmediata de los animales afectados, incluso antes de presentar fiebre u otros síntomas. Estos casos son relativamente fáciles de reconocer por su agresividad e impactante apariencia. En general, se reconocen tres niveles de virulencia en PPA: aislados de alta, moderada y baja virulencia, que se asocian con al menos cinco formas clínicas: sobreaguda, aguda, subaguda, crónica y asintomática (Tabla 1).

A pesar de que los cuadros clínicos descritos en la Tabla 1 presentan con mayor o menor frecuencia los distintos síntomas y lesiones, es importante considerarlos en conjunto durante un diagnóstico, ya que todas las presentaciones pueden observarse, sin que sean exclusivas para uno u otro grado de virulencia. En términos generales, los animales que presentan casos sobreagudos no llegan a desarrollar anticuerpos y, a medida que se empeora el estado físico, tienden a agregarse para compensar la hipotermia posterior a la fiebre y se suelen observar heces sangui- 
nolentas, manchas de sangre en las paredes y suelo de la porqueriza, vómitos, desorientación, a veces incluso convulsiones nerviosas. Los cuadros agudos que se alargan lo suficiente para que el animal responda inmunológicamente y tienen mayores posibilidades de sobrevivir o evolucionar a una forma subaguda o crónica. En estos cuadros lo más habitual es una temperatura normal o levemente febril, letargia, inapetencia, diarreas no necesariamente hemorrágicas, disneas y tos persistente. Su evolución puede llevar a la total recuperación del animal, o a la aparición progresiva de melenas, epistaxis, eritema generalizado, otros signos previamente descritos y muerte.

En los casos de baja virulencia y en los de recuperación después de la enfermedad no suele observarse fiebre, el comportamiento es aparentemente normal, y lo más llamativo son abortos, retraso de crecimiento, conjuntivitis, tos crónica, artritis y dificultades en la movilidad, necrosis focales en la piel, cianosis, cambios de pigmentación, hematomas subcutáneos o zonas enrojecidas en la piel que terminan ulcerándose; además de muertes esporádicas de animales caquécticos. Los animales con enfermedad crónica sobreviven durante meses, y a veces no mueren por PPA. Se han observado casos de individuos que parecen completamente normales por años.

En la necropsia se pueden encontrar desde lesiones considerables y hemorragias hasta ausencia total de signos de la enfermedad. Los hallazgos más sospechosos son ganglios linfáticos hemorrágicos o marmolados, hipertrofiados (especialmente los gastrohepáticos, submandibulares y renales); edema, neumonía o consolidación pulmonar con exudados espumosos en bronquios y tráquea; bazo agrandado, hemorrágico, friable o infartado; petequias y hemorragias renales; ascitis y congestión, petequias o hemorragias en órganos abdominales.

\section{Diagnóstico confirmatorio y diferencial en el laboratorio}

La PPA se incluye dentro de un grupo de enfermedades, denominadas como "enfermedades rojas del cerdo" que reúnen características clínicas y post mortem similares, y que hacen que el diagnóstico diferencial de laboratorio sea imprescindible. Es particularmente importante distinguirlo de la peste porcina clásica (PPC). Por ello, es fundamental que ante cualquier signo clínico o post mortem de los mencionados, se envíen muestras al laboratorio.

Se recomienda el envío simultáneo de muestras para la detección de antígeno y de anticuerpos; es decir, sangre y suero, en caso de un animal vivo. Si se hace una necropsia, se aconseja tomar muestras de bazo, amígdalas, y ganglios. Es necesario hacer énfasis en la importancia del uso simultáneo de técnicas virológicas (detección de virus) y serológicas (detección de anticuerpos específicos), como son la reacción en cadena de la polimerasa (PCR) y enzimoinmunoanálisis (ELISA) indirecto. Para ambas técnicas existen distintas opciones, tanto comerciales como particulares. Cualquier método utilizado debe estar validado o tener datos publicados y fiables de sensibilidad y especificidad. El incremento de esta enfermedad en los últimos años ha favorecido la proliferación de métodos de diagnóstico por lo que sería difícil entrar en detalle, pero los más utilizados se citan en la Tabla 2 
Tabla 2. Métodos de laboratorio para diagnóstico confirmatorio y diferencial de la peste porcina africana ${ }^{1}$

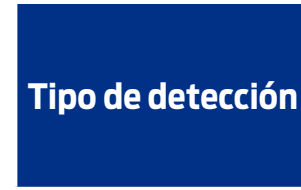

Virus vivo

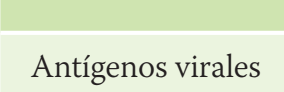

Acido nucleico

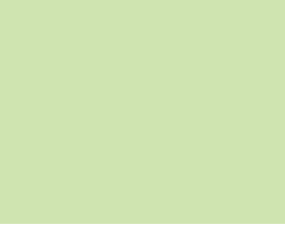

Anticuerpos

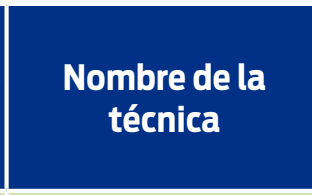

Aislamiento

Inmuno

fluorescencia directa

Cromatógrafico portátil

ELISA de antígeno

PCR convencional
PCR multiplex

PCR en tiempo real

\begin{tabular}{|c|}
\hline ELISA \\
\hline $\begin{array}{c}\text { Inmuno fluorescencia } \\
\text { indirecta }\end{array}$ \\
\hline Cromatógrafico \\
\hline Histoquímico \\
\hline
\end{tabular}

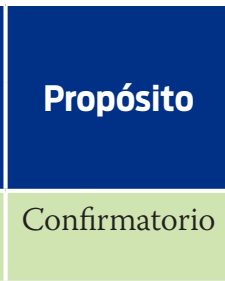

Confirmatorio

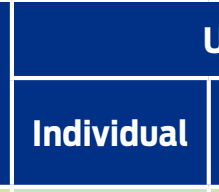

Uso recomendado

Sí

Sí

Sí

Vigilancia

Vigilancia

Confirmatorio
y vigilancia

Diferencial y confirmatorio

Confirmatorio

Confirmatorio

$\begin{gathered}\text { Confirmatorio } \\ \text { y vigilancia }\end{gathered}$
Confirmatorio

Confirmatorio

Confirmatorio

No

No

Sí

Si

Si

Sí

Sí

Sí

Sí

Sí

Sí

Sí

Rebaño

Opcional

Opcional

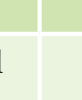

Sí

Sí

Sí

Sí

Sí

S

Sí

Sí

epic

\section{Encuesta epidemiológica}

Opcional

Opcional

Opc

Sí

\begin{tabular}{|c|c|}
\hline Sí & Sí \\
\hline No & No \\
\hline No & No \\
\hline
\end{tabular}

Sí

\begin{tabular}{|c|c|}
\hline $\begin{array}{c}\text { Referencias } \\
\text { bibliográficas/ } \\
\text { comercial }\end{array}$ \\
\hline OIE \\
No comercial \\
\hline OIE
\end{tabular}

OIE

Sí

Comercial

Comercial

Opcional

Opcional

pcional

\begin{tabular}{|c|}
\hline OIE \\
Comercial \\
\hline OIE \\
\hline Comerciales \\
\hline OIE \\
\hline OIE \\
\hline Comercial \\
\hline OIE \\
\hline
\end{tabular}

La implementación correcta de las técnicas de diagnóstico puede ofrecer respuestas que ayudan, además, a esclarecer la epidemiología. No hay que olvidar que, si bien el diagnóstico de anticuerpos por ELISA es eficiente, simple, barato y manejable para grandes números de muestras, es necesario esperar a que haya respuesta inmune. Esto impide una detección precoz de la enfermedad, que sí podría conseguirse con el uso del PCR. Por otro lado, si los síntomas son poco evidentes, o si se trata de un aislado de baja virulencia en el que sólo se observan neumonías crónicas y abortos, los anticuerpos podrían ser la única evidencia rescatable para ayudar a averiguar el origen del brote, aunque indique que no se trata de una infección reciente. Es esencial que las muestras enviadas al laboratorio se tomen apropiadamente y vayan acompañadas de una buena historia clínica, que ayude a elegir las técnicas que permitan obtener una correcta interpretación de los resultados. Para mejorar el sistema diagnóstico es por lo tanto esencial utilizar conocimientos de patología, resistencia viral y epidemiología.

Durante la fase clínica de la infección tanto el virus como el ADN viral pueden ser detectados en todas las secreciones y excreciones de los animales enfermos por aislamiento viral y PCR, respectivamente. No obstante, el laboratorio debe contemplar siempre la posibilidad de una sospecha de contaminación, de un resultado ambiguo, e incluso de un falso positivo por motivos accidentales o de reacción cruzada. Por lo tanto, antes de declarar un brote de PPA, es nece- 
sario utilizar un método diagnóstico alternativo que ratifique la presencia de la infección. Se puede utilizar, por ejemplo, una segunda PCR dirigida a una región genómica distinta a la utilizada previamente, confirmar la presencia de virus activo a través de su aislamiento en cultivos celulares, o analizar la posible vía de ingreso del virus aislado mediante su caracterización genética. Para confirmar resultados positivos o inconclusos de presencia de anticuerpos contra PPA en ELISA se recomiendan las técnicas de tinción de anticuerpos (ITB/IPT/IFI), que son muy específicas, aunque laboriosas. Los métodos confirmatorios pueden no siempre estar a disposición de los laboratorios regionales, por lo que las muestras originales se pueden enviar a algún laboratorio de referencia.

Una vez que se declara la presencia de la enfermedad, los resultados positivos y negativos obtenidos con cualquiera de las técnicas son considerados válidos siempre y cuando existan todos los controles en los análisis, y solo se necesitará proceder a la confirmación en aquellos casos cuya interpretación es ambigua o incierta.

Para el diagnóstico diferencial en el laboratorio se recomienda la inclusión de otras enfermedades virales como la PPC, la enfermedad de Aujesky, el mal rojo del cerdo o la seudorrabia (PHV-1), el síndrome respiratorio y reproductivo porcino (PRRS), el circovirus y otros síndromes porcinos de malnutrición (PDNS), además de septicemias y enfermedades bacteriana del tipo salmonelosis y pasteurelosis, e intoxicaciones alimentarias. ${ }^{1}$

\section{Medidas preventivas}

Las medidas de control para la PPA se basan en políticas agresivas de sacrificio y vigilancia. En los países en los que ha habido brotes de la enfermedad, se establecen cordones sanitarios de aproximadamente $10 \mathrm{~km}$ a la redonda del área de foco epidémico en los que se ejerce un férreo control para los vehículos que acarrean animales vivos o muertos, así como alimento para animales o subproductos animales. $1,5,6,8$

Además, dentro de los $10 \mathrm{~km}$ de las zonas de control periféricas al sitio de detección de la enfermedad, los cerdos silvestres y los jabalíes deben ser abatidos y muestreados con gran rapidez para evitar la propagación del virus. En algunos casos se recomienda incluso la construcción de vallas para garantizar la separación física entre zonas de riesgo y zonas libres de la enfermedad. La globalización y los sistemas modernos de producción porcina, así como la ausencia de una vacuna y la implicación de hospedadores intermediarios como el cerdo silvestre y las garrapatas, hacen que el control se base en bioseguridad y regionalización (colaboración internacional). Se recomienda que sea el propio órgano ejecutor del gobierno de cada país el que priorice el establecimiento de las más altas medidas de bioseguridad tanto a nivel de las granjas como de las carreteras y vida silvestre. Deben desarrollarse asimismo planes de contingencia, reacción a emergencias y apoyo económico para prevenir la entrada de la enfermedad. 
Tabla 3. Resistencia del virus de la peste porcina africana ante diferentes condiciones físicas y químicas, incluyendo agentes normalmente utilizados para la desinfección en unidades productivas

\begin{tabular}{|c|c|c|c|c|}
\hline \multicolumn{3}{|c|}{ Condiciones } & Resistencia & Referencias \\
\hline \multirow[t]{11}{*}{ Temperatura } & \multirow[t]{6}{*}{ Medioambiente } & $-20^{\circ} \mathrm{C}$ & indefinidamente & \multirow[t]{4}{*}{42} \\
\hline & & $4{ }^{\circ} \mathrm{C}$ & & \\
\hline & & $21{ }^{\circ} \mathrm{C}$ & & \\
\hline & & $37^{\circ} \mathrm{C}$ & & \\
\hline & & $56^{\circ} \mathrm{C}$ & $70 \mathrm{~min}$ & \multirow[t]{2}{*}{43} \\
\hline & & $60^{\circ} \mathrm{C}$ & $20 \mathrm{~min}$ & \\
\hline & \multirow[t]{2}{*}{ Estiércol } & $4{ }^{\circ} \mathrm{C}$ & 160 días & \multirow[t]{2}{*}{44} \\
\hline & & $37^{\circ} \mathrm{C}$ & 4 días & \\
\hline & \multirow[t]{3}{*}{ Efluentes } & $4^{\circ}{ }^{\circ} \mathrm{C}$ & 112 días & \multirow[t]{3}{*}{44,47} \\
\hline & & $17^{\circ} \mathrm{C}$ & 84 días & \\
\hline & & $37^{\circ} \mathrm{C}$ & 3 días & \\
\hline \multirow[t]{3}{*}{ Suelo } & \multirow[t]{2}{*}{ Bosque } & Verano & 3 semanas & \multirow[t]{2}{*}{42} \\
\hline & & Invierno & 13 semanas & \\
\hline & Corral & & 1 mes & 44 \\
\hline \multirow[t]{4}{*}{$\mathrm{pH}$} & $<3.9$ & Medio & \multirow[t]{2}{*}{ Pocos minutos } & \multirow[t]{2}{*}{42,47} \\
\hline & $>11.5$ & Medio & & \\
\hline & \multirow[t]{2}{*}{13.4} & Medio & 21 horas & \multirow[t]{2}{*}{42} \\
\hline & & En $25 \%$ suero & 7 días & \\
\hline \multirow[t]{6}{*}{ Químicos } & Éter & & Pocos minutos & \multirow[t]{6}{*}{47} \\
\hline & Cloroformo & & Pocos minutos & \\
\hline & Hidróxido de sodio (0.8\%) & & $30 \mathrm{~min}$ & \\
\hline & Hipoclorito de sodio (2.3\%) & & $3 \mathrm{~min}$ & \\
\hline & Formalina $(0.3 \%)$ & & $30 \mathrm{~min}$ & \\
\hline & $\begin{array}{l}\text { Ortofenoles y compuestos de } \\
\text { yodo (3\%) }\end{array}$ & & $30 \mathrm{~min}$ & \\
\hline \multirow[t]{6}{*}{ Materia orgánica } & $\begin{array}{l}\text { Sangre, vísceras, médula ósea y } \\
\text { músculo }\end{array}$ & $4{ }^{\circ} \mathrm{C}$ & Hasta 18 meses & 42 \\
\hline & Heces, orina y estiércol & $21{ }^{\circ} \mathrm{C}$ & 11 días & 42,47 \\
\hline & \multirow[t]{3}{*}{ Productos cárnicos no cocinados } & $-20^{\circ} \mathrm{C}$ & 1000 días & 41 \\
\hline & & $4^{\circ} \mathrm{C}$ & 110 días & 41 \\
\hline & & $21{ }^{\circ} \mathrm{C}$ & De 105 a 300 días & 41 \\
\hline & En putrefacción & & 15 semanas & 41 \\
\hline
\end{tabular}


Para tomar medidas de bioseguridad, control y desinfección, deben tenerse en cuenta los sitios en los que el virus puede encontrarse, así como los tratamientos que pueden utilizarse para inactivarlo. Todas las secreciones y excreciones de un animal infectado contienen gran cantidad de virus infeccioso. ${ }^{41}$ Además, el virus es sorprendentemente resistente a las condiciones ambientales (Tabla 3), lo que es determinante para su transmisión. De hecho, su resistencia y estabilidad tanto en condiciones ambientales como de almacenamiento permiten que el virus de la PPA permanezca infeccioso durante largos periodos, principalmente en un ambiente rico en proteínas. Su presencia en productos comestibles, tales como carne refrigerada y productos crudos curados no cocinados, puede tener importantes implicaciones para la propagación de la PPA, teniendo en cuenta que la dosis infecciosa para cerdos domésticos es de tan solo de 1 a 10 TCID50 en alimento líquido y 104 TCID50 en alimento sólido. De igual forma, se considera que uno de los modos más comunes de transmisión e introducción de la enfermedad en zonas libres es por el transporte de objetos, ropa, productos o artículos personales accidentalmente contaminados.

La aptitud del virus para conservar su capacidad infecciosa en distintos escenarios ambientales, y su resistencia a las condiciones físicas y agentes químicos que generalmente se utilizan para proteger y desinfectar tanto unidades de producción porcina doméstica como en vida silvestre, se presentan en la Tabla 3.

\section{Epidemiología y control}

La PPA fue puesta de manifiesto al introducir cerdos domésticos provenientes de Europa en granjas africanas en 1921. Se demostró que la enfermedad procedía de cerdos silvestres (Phacochoerus africanus), clínicamente normales que, junto con las garrapatas infestadas, actuaban como reservorios del virus, dentro de una simbiosis establecida o ciclo selvático ancestral. Algunos autores sugieren que probablemente la introducción del cerdo doméstico produjo un cambio en este equilibrio natural; es decir, que fue el detonante para la manifestación de una infección que antes existía sin la presentación de un cuadro clínico asociado al agente infeccioso. Sea como fuere, lo importante es que también surgió la transmisión directa del virus entre hospedadores (sin las garrapatas como vector), que resultó en una nueva amenaza para los animales de producción y estableció a la PPA como un grave problema económico hasta nuestros días. En Europa, el cerdo salvaje y el jabalí son los principales reservorios en la naturaleza. A diferencia del cerdo silvestre africano, tanto el cerdo montaraz como el jabalí sufren la misma enfermedad que el cerdo doméstico y tienen un papel fundamental en la expansión y transmisión del virus. Los cadáveres de los animales silvestres muertos por la enfermedad quedan expuestos en el campo y son fuente de contaminación durante largos periodos. ${ }^{14,15,48,49}$

El papel que desempeñan las garrapatas Ornithodoros que habitan las porquerizas en el mantenimiento y transmisión de la PPA se ha demostrado tanto en África como en Europa. En la península ibérica, Ornithodoros erraticus 
contribuyó significativamente a la situación endémica, y es muy probable que haya sido responsable del brote de 1999 en Portugal, en el que los cerdos fueron introducidos en porquerizas abandonadas que todavía estaban habitadas por garrapatas. Sin embargo, en Cerdeña no hay garrapatas Ornithodoros, y a pesar de que algunas especies se encuentran en el Caribe y en América del Norte que son capaces de mantener y transmitir el virus de PPA, la experiencia con los brotes de PPA que han ocurrido en el Caribe indica que dichos vectores no participaron en la transmisión de la enfermedad. Igualmente, en el caso reciente en los estados Bálticos y en Polonia, el papel más predominante en la transmisión de PPA parece haberlo tenido el jabalí, a través de los corredores naturales de migración de estos animales en la naturaleza, y no las garrapatas.

El hecho de que no existan vacunas que ayuden en el control de la PPA acentúa el que la calidad de los métodos de diagnóstico y la capacidad de detección temprana sean las más importantes herramientas para contrarrestar los efectos devastadores de la enfermedad. Como parte integral de dichas medidas están la eliminación de animales afectados, el establecimiento de zonas de acceso y movimientos animales restringidos, los sistemas de trazabilidad y el tratamiento correcto de residuos y cadáveres. La mayor dificultad está en el control de la fauna silvestre, la cual actúa como reservorio del virus y fuente de reinfección de animales domésticos.

Como consecuencia de los grandes esfuerzos hechos por los países afectados para despoblar granjas enteras donde hubo sospecha de PPA, se aprendió que la enfermedad cambia con el número de ciclos de infección y concluye con contagios procedentes de animales aparentemente asintomáticos. Del mismo modo, se sabe que el virus es capaz de dar enormes saltos geográficos sin una aparente relación entre dos focos, probablemente debido a un transporte indirecto, o a la transmisión por animales silvestres que muestran resistencia a los síntomas agudos de la enfermedad. La conclusión es que los fundamentos básicos de los escenarios epidemiológicos se desconocen y varían para cada situación. De ello se desprende que los métodos de diagnóstico pueden tener una eficiencia variable, dependiendo del panorama en el que se desenvuelvan los acontecimientos. La serología pudiera no ser de gran ayuda por ejemplo durante los primeros casos clínicos de cerdos de granja que mueren rápidamente, pero ser la mejor opción para detectar la enfermedad en los porcinos silvestres, o cuando ya no se observan casos clínicos fulminantes. Es probable que cada plan necesite ser diseñado a la medida de las circunstancias epidémicas presentes en cada momento y lugar.

En resumen, incrementar los conocimientos relativos a la biología de la enfermedad, la transparencia en los resultados del diagnóstico, las campañas de vigilancia, y la fluidez de la información epidemiológica son aspectos fundamentales para apoyar las estrategias actuales de control, que se basan en la detección rápida, el sacrificio inmediato de animales confirmados y sospechosos de infección, y la implementación de cuarentenas eficaces. 


\section{Conclusiones y recomendaciones}

Lograr una vacuna eficiente, así como mejorar los métodos de detección y caracterización de las variantes de la PPA son las tareas más apremiantes que quedan aún por resolver. Son también las tareas más difíciles y que requieren del mayor esfuerzo. Debe tenerse en cuenta que el desarrollo de una respuesta inmune neutralizante de tipo humoral en los animales infectados sigue siendo un tema de discusión entre especialistas. La alta tasa de mortalidad contrasta con los múltiples casos de enfermos crónicos y portadores asintomáticos detectados en lugares de alta endemicidad y en la vida silvestre, lo que dificulta la planificación de políticas acertadas de vigilancia, control y erradicación. En la medida en la que se declaran nuevos brotes, y se requieren acciones rápidas para la toma de decisiones, el número de análisis recibidos en el laboratorio se dispara y la disponibilidad de reactivos y materiales de origen comercial para procesarlos puede colapsarse de modo repentino. Así, la experiencia en los países afectados ha puesto en evidencia la importancia de tener un mínimo de producción local de reactivos validados y cuyo control de calidad sea aceptable. Igualmente, es importante tener un segundo método acreditado como alternativa a la imposibilidad de continuar con el originalmente en uso. Ante esta situación, habría que ampliar lo más posible el número de pruebas comerciales validadas, y apoyarse de la industria para estandarizar y abastecer a los laboratorios privados con aquellos métodos que se utilicen para la confirmación del diagnóstico.

Asimismo, se ha puesto de manifiesto que es necesario invertir en el desarrollo de productos diagnósticos y farmacéuticos de larga vida y estables a temperatura ambiente utilizando técnicas como liofilización, gelificación, conservación al vacío u otras, con el fin de evitar el uso masivo de cámaras frigoríficas para almacenamiento. Desarrollar una capacidad de alto rendimiento, robotización y acreditación de laboratorios periféricos se considera uno de los mayores aciertos en la planificación y alerta epidemiológicas.

Por último, los expertos internacionales en PPA han señalado vacíos en conocimiento y carencias instrumentales críticas para mejorar la capacidad de reacción y control de la enfermedad. Hay documentos disponibles públicamente que explican en detalle los resultados de dichos análisis de insuficiencias técnicas e intelectuales (GARA y EFSA reportes), que en síntesis proponen la necesidad de mejorar el conocimiento de la PPA en varios aspectos:

- Significado biológico y definición específica de tipos patológicos (pato-tipos), serotipos y genotipos del virus.

1 Estudio antigénico que facilite diseño de vacunas, así como el desarrollo de técnicas serológicas diferenciales y seguras.

- Identificación de receptores celulares que permitan encontrar sistemas in vitro eficaces, asépticos y asequibles para aislamiento y cultivo del virus.

- Validación de métodos portátiles y mejorados de diagnóstico (muestras ambientales, múltiples, no invasivas, transporte bioseguro de muestras, métodos de análisis rápido y a pie de granja, etc.), y que los datos se hagan 
accesibles al público general para que faciliten armonización y confiabilidad en los resultados.

- Control poblacional del cerdo silvestre y jabalí, así como sistemas de vigilancia epidemiológica de éstos. 


\section{Referencias}

1. OIE Terrestrial Manual Section 3.8. Chapter 3.8.1. African swine ferver (2019). Disponible en: https://www.oie.int/en/animal-health-in-the-world/ animal-diseases/african-swine-fever/

2. Tulman ER, Delhon GA, Ku BK, Rock DL. African swine fever virus. Curr Top Microbiol Immunol. 2009;328:43-87.

3. Tulman ER, Delhon GA, Ku BK, Rock DL. African swine fever virus. Lesser Known Large dsDNA Viruses. 2009;328;43-87.

4. Coggins L. African swine fever virus. Pathogenesis. Prog Med Virol 1974;18:48-63.

5. Global Alliance for Research in African swine Fever 2019. Gap analysis report. Disponible en: https://www.ars.usda.gov/GARA/

6. Bellini S, Rutili D, Guberti V. Preventive measures aimed at minimizing the risk of African swine fever virus spread in pig farming systems. Acta Vet Scand. 2016;58, article 82.

7. Zhou X, Li N, Luo Y, Liu Y, Miao F, Chen T, et al. Emergence of African swine fever in China, 2018. Transbound Emerg Dis. 2018;65:1482-4.

8. EFSA: Scientific Report. Reasearch gap analysis on African swine fever. Disponible en: https://efsa.onlinelibrary.wiley.com/doi/epdf/10.2903/j. efsa.2019.5811

9. Alonso C, Borca M, Dixon L, Revilla Y, Rodríguez F, Escribano JM. Ictv Report Consortium. ICTV virus taxonomy profile: Asfarviridae. J Gen Virol. 2018;99:613-4.

10. Dixon LK, Chapman DAG, Netherton CL, Upton C. African swine fever virus replication and genomics. Virus Res 2013;173:3-14.

11. Blome S, Gabriel C, Beer M. Pathogenesis of African swine fever in domestic pigs and European wild boar. Virus Res. 2013;173:122-30.

12. De Villiers EP, Gallardo C, Arias M, Da Silva M, Upton C, Martin R, et al. Phylogenomic analysis of 11 complete African swine fever virus genome sequences. Virology. 2010;400:128-36.

13. Nurmoja I, Petrov A, Breidenstein C, Zani L, Forth JH, Beer M, et al. Biological characterization of African swine fever virus genotype II strains from north-eastern Estonia in European wild boar. Transbound Emerg Dis. 2017;64, 2034-2041.

14. Montgomery RE. On a form of swine fever occurring in British East Africa (Kenya Colony). J Comp Pathol Ther. 1921;34:243-62.

15. Howey EB, O’Donnell Ferreira H, Borca MV, Arzt J. Pathogenesis of highly virulent African swine fever virus in domestic pigs exposed via intraoropharyngeal, intranasopharyngeal, and intramuscular inoculation, and by direct contact with infected pigs. Virus Research. 2013;178(2013):328-39.

16. Post J, Weesendorp E, Montoya M, Loeffen WL. Influence of age and dose of African swine fever virus infections on clinical outcome and blood parameters in pigs. Viral Immunol. 2017;30:58-69. 
17. Guinat C, Gogin A, Blome S, Keil G, Pollin R, Pfeiffer DU. Transmission routes of African swine fever virus to domestic pigs: current knowledge and future research directions. Vet Rec. 2016;178:262-7.

18. Olesen AS, Lohse L, Boklund A, Halasa T, Gallardo C, Pejsak Z, et al. Transmission of African swine fever virus from infected pigs by direct contact and aerosol routes. Vet Microbiol. 2017;211:92-102.

19. Olesen AS, Hansen MF, Rasmussen TB. Belsham GJ, Bødker R, Bøtner A. Survival and localization of African swine fever virus in stable flies (Stomoxys calcitrans) after feeding on viremic blood using a membrane feeder. Vet Microbiol. 2018;222:25-9.

20. Blome S, Gabriel C, Beer M. Pathogenesis of African swine fever in domestic pigs and European wild boar. Virus Res. 2013;173:122-30.

21. Onisk DV, Borca MV, Kutish G, Kramer E, Irusta P, Rock DL. Passively transferred African swine fever virus-antibodies protect swine against lethal infection. Virology. 1994;198:350-4

22. Ruiz-Gonzalvo F, Caballero C, Martinez J, Carnero ME. Neutralization of African swine fever virus by sera from African swine fever-resistant pigs. Am J Vet Res. 1986;47:1858-62.

23. Ruiz-Gonzalvo F, Carnero ME, Caballero C, Martinez J. Inhibition of African swine fever infection in the presence of immune sera in vivo and in vitro. Am J Vet Res. 1986;47:1249-52.

24. Burmakina G, Malogolovkin A, Tulman ER, Zsak L, Delhon G, Diel DG, et al. African swine fever virus serotype-specific proteins are significant protective antigens for African swine fever. J Gen Virol. 2016;96:866-73.

25. Afonso CL, Neilan JG, Kutish GF, Rock DL. An African swine fever virus Bc12 homolog, 5-HL, suppresses apoptotic cell death. J Virol. 1996;70:4858-63.

26. Afonso CL, Piccone ME, Zaffuto KM, Neilan J, Kutish GF, Lu Z, et al. African swine fever virus multigene family 360 and 530 genes affect host interferon response. J Virol. 2004;78(4):1858-64.

27. Basta S, Knoetig SM, Spagnuolo-Weaver M, Allan G, McCullough KC. Modulation of monocytic cell activity and virus susceptibility during differentiation into macrophages. J Immunol. 1999;162(7):3961-9.

28. Borca MV, Carrillo C, Zsak L, Laegreid WW, Kutish GF, Neilan JG, et al. Deletion of a CD2-like gene, 8-DR, from African swine fever virus affects viral infection in domestic swine. J. Virol. 1998;72:2881-9.

29. Borca MV, Kutish GF, Afonso CL, Irusta P, Carrillo C, Brun A, et al. An African swine fever virus gene with similarity to the T-lymphocyte surface-antigen Cd2 mediates hemadsorption. Virology. 1994;199:463-8.

30. Borca MV, Carrillo C, Zsak L, Laegreid WW, Kutish GF, Neilan JG, et al. Deletion of a CD2- like gene, 8-DR, from African swine fever virus affects viral infection in domestic swine. J Virol. 1998;72:2881-9.

31. Burrage TG, Lu, Z, Neilan JG, Rock DL, Zsak L. African swine fever virus multigene family 360 genes affect virus replication and generalization of infection in Ornithodoros porcinus ticks. J Virol. 2004;78:2445-53. 
32. Sanford B, Holinka LG, O'Donnell V, Krug PW, Carlson J, Alfano M, et al. Deletion of the thymidine kinase gene induces complete attenuation of the Georgia isolate of African swine fever virus. Virus Res. 2016; 213:165.

33. Ramirez-Medina E, Vuono E, O’Donnell V, Holinka LG, Silva E, Rai A, et al. Differential effect of the deletion of african swine fever virus virulence-associated genes in the induction of attenuation of the highly virulent Georgia strain. Viruses. 2019;11.

34. O’Donnell V, Risatti GR, Holinka LG, Krug P, Carlson J, Velazquez-Salinas L, et al. Simultaneous deletion of the 9GL and UK genes from the African swine fever virus Georgia 2007 isolate offers increased safety and protection against homologous challenge. J Virol. 2016;91.

35. Borca MV, Ramirez-Medina E, Silva E, Vuono E, Rai A, Pruitt S, et al. Development of a highly effective African swine fever virus vaccine by deletion of the I177L gene results in sterile immunity against the current epidemic Eurasia strain. J. Virol. 2019 [in press, Feb. 2020].

36. De Kock G, Robinson EM, Keppel JJG. DuToit PJ. Swine fever in South Africa. Onderstepoort J Vet Res Anim Ind. 1940;14:31-93.

37. Hammond RA, Detray DE. A recent case of African swine fever in Kenya, East Africa. J. Am. Vet. Med. Assoc. 126, 389-91.

38. Colgrove GS, Haelterman EO, Coggins L. Pathogenesis of African swine fever in young pigs. Am J Vet Res. 1969;30:1343-59.

39. Gallardo C, Soler A, Nieto R, Cano C, Pelayo V, Sanchez MA, et al. Experimental infection of domestic pigs with African swine fever virus Lithuania 2014 Genotype II Field Isolate. Transbound Emerg Dis. 2015;64:300-4.

40. Greig A. Pathogenesis of African swine fever in pigs naturally exposed to the disease. J Comp Pathol. 1972;82:73-9.

41. Mazur-Panasiuk N, Żmudzki J, Woźniakowski G. African swine fever virus - Persistence in different environmental conditions and the possibility of its indirect transmission. J Vet Res. 2019;63:303-10.

42. OIE Manual for Diagnostic of Terrestrial Animal Diseases. Disponible en: http://www.oie.int/esp/maladies/fiches/

43. Mebus C, Arias M, Pineda JM, Tapiador J, House C, Sánchez-Vizcaíno JM. Survival of several porcine viruses in different Spanish dry-cured meat products. Food Chem. 1997;59:555-9.

44. Davies K, Goatley LC, Guinat C, Netherton CL, Gubbins S, Dixon LK, et al. Survival of African swine fever virus in excretions from pigs experimentally infected with the Georgia 2007/1 isolate. Transbound Emerg Dis. 2015;64:425-31.

45. Kalmar ID, Cay AB, Tignon M. Sensitivity of African swine fever virus (ASFV) to heat, alkalinity and peroxide treatment in presence or absence of porcine plasma. Vet Microbiol. 2018;219:144-9.

46. Petrini S, Feliziani F, Casciari C, Giammarioli M, Torresi C, De Mia GM. Survival of African swine fever virus (ASFV) in various traditional Italian dry-cured meat products. Prev Vet Med. 2019;162:126-30. 
47. Plowright W, Parker J. The stability of African swine fever virus with particular reference to heat and $\mathrm{pH}$ inactivation. Arch Gesamte Virusforsch. 1967;21:383-402.

48. Niederwerder MC, Stoian AMM, Rowland RRR, Dritz SS, Petrovan V, Constance LA, et al. Infectious dose of African swine fever virus when consumed naturally in liquid or feed. Emerg Infect Dis. 2019;25:891-7.

49. Pietschmann J, Guinat C, Beer M, Pronin V, Tauscher K, Petrov A, et al. Course and transmission characteristics of oral low-dose infection of domestic pigs and European wild boar with a Caucasian African swine fever virus isolate. Arch Virol. 2015;160:1657-67.

\section{Enlaces de interés}

OIE World Animal Health Information System. Disponible en: http://www.oie.int/ wahis_2/public/wahid.php/Reviewreport/Review/viewsummary/report; https://www.oie.int/en/animal-health-in-the-world/information-on-aquaticand-terrestrial-animal-diseases/african-swine-fever/reports-on-asf

Global Alliance for Research in African swine Fever 2019 Gap analysis report. Disponible en: https://www.ars.usda.gov/GARA/

European Food Safety Authority: African swine fever. Disponible en: https:// www.efsa.europa.eu/en/topics/topic/african-swine-fever

Africanswinefever(ASF) detectionanddiagnosis. Amanualforveterinarians(2017). Disponible en: https://www.pork.org/african-swine-fever-need-know/

African Swine Fever in wild boar. Ecology and biosecurity. Disponible en: https://eaphm.org/news/faooie-manual-african-swine-fever-wild-boar-ecology-and-biosecurity

FAO-Animal production and health: ASF situation update. Disponible en: http:// www.fao.org/ag/againfo/programmes/en/empres/ASF/Situation_update. html

FAO FOOD OUTLOOK. Biannual report on global food markets. Disponible en: http://www.fao.org

Manual on the preparation of African swine fever contingency plans. Disponible en: http://www.fao.org/ag/againfo/programmes/en/empres/documents/ ASF_Manual1_ContingencyPlan.pdf

African Swine fever Standard Operating Procedures: FAD PReP Foreign Animal Disease Preparedness and Response Plan USDA-APHIS (2018). Disponible en: https://www.aphis.usda.gov/animal_health/emergency_management/ downloads/sop/sop_asf_e-e.pdf

Guberti V, Khomenko S, Masiulis M, Kerba S. African swine fever in wild boar ecology and biosecurity. FAO Animal Production and Health Manual No. 22. Rome: FAO, OIE y EC; 2019. Disponible en: http://www.fao.org/3/ca5987en/ CA5987EN.pdf 